This is a self-archived - parallel published version of this article in the publication archive of the University of Vaasa. It might differ from the original.

\title{
Disclosing Principles of IR Communication: Rhetorical Moves for Constructing Transparency
}

\author{
Author(s): Koskela, Merja \\ Title: Disclosing Principles of IR Communication: Rhetorical Moves \\ for Constructing Transparency \\ Year: $\quad 2017$ \\ Version: Final draft (post print, aam) \\ Copyright SAGE Publications
}

Please cite the original version:

Koskela, M. (2017). Disclosing Principles of IR Communication: Rhetorical Moves for Constructing Transparency. International journal of business communication. 55(2), 164-193. https://doi.org/10.1177/2329488417735645 


\section{Disclosing principles of IR communication - Rhetorical moves for constructing transparency}

Merja Koskela, University of Vaasa

\section{This is a final post-refereeing draft of:}

Koskela, Merja (2017). Disclosing principles of disclosure - Rhetorical moves for constructing transparency. International Journal of Business Communication Vol. 55(2), 164-193. DOI:

10.1177/2329488417735645

Transparency has become a keyword in discussions of accountability for business conduct. For example, the EU issued a Transparency Directive in 2004 (2004/109/EC; revised in 2013/50/EU), that aims to guarantee a regular flow of financial information to the market. However, there is no clear consensus of what transparency means in this context. For example, O'Neill (2006, p. 83) is concerned that transparency in this sense is focused on what the companies choose to disclose but not on the form of the disclosure, while Albu and Wehmeier (2014, p. 129-130) emphasize the role of stakeholders in creating transparency and highlight the importance of constructing understandable and relevant messages that are rhetorically sound.

In addition to the EU directive and national legislation, there is also a specific internationally recognized genre devoted to ensuring transparency among listed companies. According to Guimard (2008, p. 150), a written disclosure policy document is increasingly becoming a best practice in Investor Relations (IR) communication internationally. According to the author (p. 150-151), disclosure policies explain to employees what working in a listed company means in 
terms of relevant rules and regulations concerning communication, for example, when communicating with reporters and other outsiders. For the markets, the policies deliver information about what and when the company publishes according to which disclosure principles, frequency of publishing, as well as information about when the company is not communicating with the markets (quiet period). In line with these international best practices, for example the Finnish Financial Supervisory Authority (2013a) recommends that listed companies should describe their principles of financial communication on their investor relations (IR) websites. Accordingly, the Investor Relations websites of many Finnish companies include a disclosure policy, defined as a communication strategy document that outlines how companies define their IR communication strategies and practices (Koskela \& Kuronen, 2014).

These voluntary documents can be said to form a genre since they have a shared communicative purpose recognized by practitioners, a title, and an established structure (see Askehave \& Swales, 2001). As shown by Koskela and Kuronen (2014), disclosure policies have the status of a genre in the Finnish context because there is a discourse community which regularly uses it to achieve certain goals. Studying these documents can shed light on how listed companies understand financial communication in general and more specifically how they interpret what transparency means for them. Therefore, the aim of this paper is to discuss how listed companies communicate their interpretation of transparency to the market through the disclosure policy genre. The communicative purpose of the policy is to deliver a transparent image of the company, but it may also be used for other purposes, such as to gain a competitive advantage (Koskela \& Kuronen, 2014). 
This paper makes a contribution to genre analysis as it offers a description of the rhetorical moves constituting the disclosure policy genre and illustrates how they serve the construction of transparency. In terms of transparency research, this paper takes a position between the tradition of studying what transparency is and that discussing what transparency does (Christensen \& Cheney, 2015). However, this research focuses primarily on the latter because disclosure policy as a genre is seen as a response to societal transparency requirements (see Garzone, 2012). Therefore, the interpretation of transparency delivered through the disclosure policy genre may be based on an ideal with little relation to reality (see Stevens, Steensma, Harrison, \& Cochran, 2005; Albu \& Wehmeier, 2014). Nevertheless, the idealized presentation of transparency is interesting because it reveals what companies think stakeholders want. The genre is shaped by the norms and expectations of the relevant actors, while it simultaneously shapes them both and plays a role in the transparency construction of the companies.

\section{Defining transparency}

There is a substantial body of research in different disciplines that discusses transparency as a communicative practice required of corporations and listed companies (notably a special issue of the European Journal of Social Theory in 2015, see Hansen, Christensen, \& Flyverbom, 2015). In their illuminating discussion of the concept, Albu and Wehmeier (2014, p. 117) conclude that transparency is a dynamic and relational phenomenon that has been defined, evaluated, and implemented in very different ways depending on the researchers' perspective. They also state that current PR literature tends to present transparency as connected with mutual exchange and comprehensibility, but despite that, often resorts to simplistic definitions. These include equating transparency with honesty, seeing it as the opposite of manipulation, bias, and advertising, or 
simply referring to it as information giving and information sharing (p. 118). Other equally straightforward definitions include seeing transparency as a synonym for good governance, information access and provision, as well as information availability (Christensen \& Cheney, 2015, p. 72-76).

In a similar vein, Christensen and Cheney (2015, p. 72) comment on the diversity of meanings and applications of transparency. They study transparency as a social value at the organizational level because it is there that it translates into practices and policies. It is also there that it is possible to concentrate on what transparency does in contrast to what transparency is. In fact, Christensen and Cheney (p. 73, 74-75) suspect that the ways in which transparency is put into practice may undermine the core idea of the concept. This is because practitioners tend to see communication as a neutral transfer of information free of communication-related complexities. In other words, there is an underlying assumption that senders are acquiescent and omniscient, messages are neutral and uncontaminated and receivers are competent, involved and able (and willing) to understand the messages as they were intended (p. 74). Naturally, this is never the case in reality. On the contrary, communication that serves transparency is always "an ambiguous practice of representation" (p. 78). Interestingly, this is why "policies of consistency" such as disclosure policies are designed, enabling (or offering the illusion to) organizations, to a degree, to formalize their communications, and to unify disparate organizational voices (see Christensen \& Langer, 2009).

The disclosure policy genre with a rather regular content and structure serves a purpose in transparency construction for listed companies, because addressing the question of transparency always has a downside. While delivering the ideal of openness and trust, claims of transparency 
also make visible the antonyms of transparency, such as opacity, concealment, corruption, and mistrust. That being the case, transparency practices can actually foment uncertainty and suspicion (Hansen et al., 2015, p. 120). However, an established genre shared by several companies reproducing and communicating a similar ideal may mitigate against negative interpretations and consequences. Nevertheless, companies need to stay alert because transparency is something constantly in the making.

Despite the obvious usefulness of policy genres, there are conflicting views about their effectiveness. Stevens et al. (2005) describe policies guiding executive decisions as substantive documents in contrast to symbolic documents, meaning documents that are not applied in practice and which do not affect decision making. In their study of corporate codes of ethics and managers' decision-making processes, Stevens et al. (2005) show that the effectiveness of ethical codes, comparable with disclosure policies, is dependent on the degree to which executives believe in them. The stronger the belief in their effect, the more effective the ethical codes prove to be. In addition, regulatory pressure is less efficient than stakeholder pressure, which is very effective if the executives see the policies as assets for creating a positive image of the company. When there is external pressure to declare transparency, there is the risk that disclosure policies may become symbolic documents in the sense that they are written and published just to show awareness of the issues, but do not necessarily guide actual behavior. Indeed, disclosure policies may present a prime example of de-coupling declarations from deeds: disclosure policy may be used to deliver an image of openness to the public, which internal company forces might effectively counter (Hansen et al., 2015, p. 120). 
In the present paper, transparency is understood as a discursive and rhetorical construction created and developed in the communicative practices of financial communication. Ideally the goal of transparency is to ensure that the actions and decisions taken by an organization are "ascertainable and understandable" for the key actors. This requires active participation by stakeholders and the wider public. (Albu \& Wehmeier, 2014, p. 119) In other words, there is no transparency without an attentive public that is able to receive relevant messages on and from the organization, interpret them, and make sense of them (Christensen \& Langer, 2009).

\section{Prior studies of policy texts}

Disclosure policy belongs to the large and variable group of communication strategy texts (see e.g., Koskela, 2013). This paper draws on two types of earlier research: research on strategy texts in general and research on communication strategies in particular. Below, I will briefly characterize some representative examples of both types of research, but focus the literature review on those methodologically relevant (i.e., mainly genre-based studies).

Textual analysis of strategy texts has been called for, especially in the strategy-as-practice research (e.g., Jarzabkowski \& Whittington, 2008; McCabe, 2010), and several discourse analysts have obliged. For example, Vaara, Sorsa, and Pälli (2010) found that the institutionalized use of strategic language typical of the strategy genre reflects the force potential of these texts as powerful devices promoting and legitimating specific objectives. It is therefore to be expected that transparency as a specific objective is promoted in disclosure policy texts through specific discursive characteristics that strive to have an impact on the performative effect of the genre. 
In their genre-based study of a large corpus of strategic plans from public and third sector organizations, Cornut, Giroux, and Langley (2012) find that strategic plans are linguistically unique in many respects. According to them, the strategy genre tends to be based on standard textual formula from which organizations must be able to deviate if the context so requires (p. 47). Accordingly, disclosure policy texts as representatives of the strategy genre may contain at least some of the prototypical rhetorical moves found in other types of strategic plans. These include a statement of the vision and mission, a description of the strategy planning process, priorities and goals, implementation activities, and responsibilities (Cornut et al., 2012, p. 39). However, more than the moves of strategies in general, the rhetorical structure of disclosure policies probably reflects the specific communicative purpose of the genre as well as companyspecific priorities.

The importance of company-specific priorities is also highlighted by Gilsdorf $(1987 ; 1992)$ in her seminal empirical research of communication strategy texts. Stating that each organization should shape its communication policy according to its own needs, she recommends that policy texts should remain "concise, memorable and well-fitted to the organization" (Gilsdorf, 1992, p. 342). Moreover, Steyn (2003) recommends that corporate communication strategy should be an emergent rather than a deliberate strategy because its goals are based on a continuous analysis of stakeholders' needs and key strategic issues. An emergent strategy "is evolving and incremental, with elements still developing as the strategy unfolds" (p. 21). When it comes to disclosure policies, they seem to be deliberate strategies with their own communicative purposes. 
An important aspect of fitting a policy to the organization is the close connection between communication policy texts and other strategic and operational documents. In an empirical study of the communication policies of Danish municipalities, Grove Ditlevsen and Kastberg (2007, p. 33-34) found that such connections may be openly stated or only implied. According to their study, there were only three shared constitutive content elements in the data: 1) principles, values, visions, and goals, 2) rules, and 3) audiences (ibid. p. 31). The elements as such seem to be in line with the results by Cornut et al. (2012). The extensive variation was explained by the fact that communication policy is an emerging genre as it is new in the public sector. Comparably, the degree of potential variation in disclosure policy texts may be explained by the relative newness of the genre, but also by the need to be organization-specific.

Further highlighting the intertextual character of communication strategy texts, Koskela (2013) applies intertextual analysis to a genre system of communication strategy texts to discern if and how genre borders can be drawn between texts with different genre labels. The data include four texts: a communication strategy and an information policy (company-internal documents), and a communication policy and a disclosure policy (company-external public documents) (p. 394). The results of the analysis reveal little difference in the intertextual profile of the documents, but that they have different interdiscursive ties resulting from different audiences and the function of the documents as parts of different types of professional practices. Publicly available documents focus on stock markets and the legal regulation of the communication of listed companies, indicating that they are at least partly a result of regulatory pressure. In particular, the disclosure policy document seems to perform a dual function, sharing features with the other texts as it is 
used to guide the communication function of the company, but differing from them because it constitutes a response to the market authorities, investors, and analysts (p. 399).

This paper continues the qualitative case-study of 11 disclosure policies of Finnish listed companies carried out by Koskela and Kuronen (2014). Based on Bhatia's (1993; 2004) multidimensional approach to genre analysis, they study variation caused by the different social practices that disclosure policies enact in the business context. The variations identified seem to be related to how the disclosure policies were placed in the website context, their length and content, and particularly to their intertextual and interdiscursive ties.

Koskela and Kuronen (2014) identified three communicative purposes for the disclosure policy documents. First, the policies are written in order to convince investors of the reliability of the company as an investment object, and the disclosure policy genre thus functions as an instrument for projecting an image of transparency to the public. Second, the policy texts serve as internal guidance for employees working on financial communication. (See also Guimard, 2008, p. 150.) Third, a disclosure policy fulfills legal requirements and recommendations as it testifies to the company following the recommendations of the stock market and authorities. (Koskela \& Kuronen, 2014; Ditlevsen, 2014) The disclosure policy of a company may be drawn toward any of the three communicative purposes according to the company goals. For example, highlighting the function as being one of internal instruction tends to require longer and more detailed texts, while conforming to a regulatory requirement or recommendation can be achieved with a relatively short and general text. The three communicative purposes which texts primarily serve also influence the intertextual features of the genre. As a standardized discursive response to 
societal transparency requirements (see Garzone, 2012), the disclosure policy genre is inherently intertextual because it originates from authoritative sources (see Figure 1).

In addition to reflecting the societal context, disclosure policies are shaped by the genre system they belong to. For example, Albu and Wehmeier (2014, p. 117) report the increasing requirement for policies, codes of conduct, and social standards in contemporary society. In this sense, disclosure policies can be seen as belonging to the same genre system as a code of ethics, corporate governance statement et cetera, a genre system we might describe as made up of statement genres. Ohlsson (2011) asserts that such documents are necessary public documents which many international corporations produce, and use in similar ways, which testifies to the reciprocity between language-in-use and social practices. As voluntary instruments of selfregulation, these texts share certain intertextual and interdiscursive characteristics.

According to Koskela and Kuronen (2014), further research on the linguistic and textual features of disclosure policies is merited in order to understand better how diverse semiotic resources are used rhetorically in order to serve the variable communicative purposes of the genre. This paper fills this research gap with respect to transparency descriptions.

\section{The normative background of the disclosure policy genre}

In order to restore trust in the financial markets after several financial scandals in the 2000 s, new regulations concerning transparency and openness have been introduced globally. These include The Regulation for Fair Disclosure in the USA in 2001, as well as the Transparency Directive (2004/109/EC; 2013/50/EU) and the Market Abuse Directive (EU 596/2014/MAR) in Europe. 
The implementation of these regulations has led to a dynamic development of best practices in listed companies, including the publishing a written disclosure policy (Guimard, 2008, p. 58, $150)$.

In the Finnish context, the disclosure policy genre has been introduced to listed companies by the Financial Supervisory Authority (see 2008), affecting its status and making it subject to changing regulations for transparency creation during the last 15 years. The timeline of the development of regulations and recommendations is presented in Figure 1.

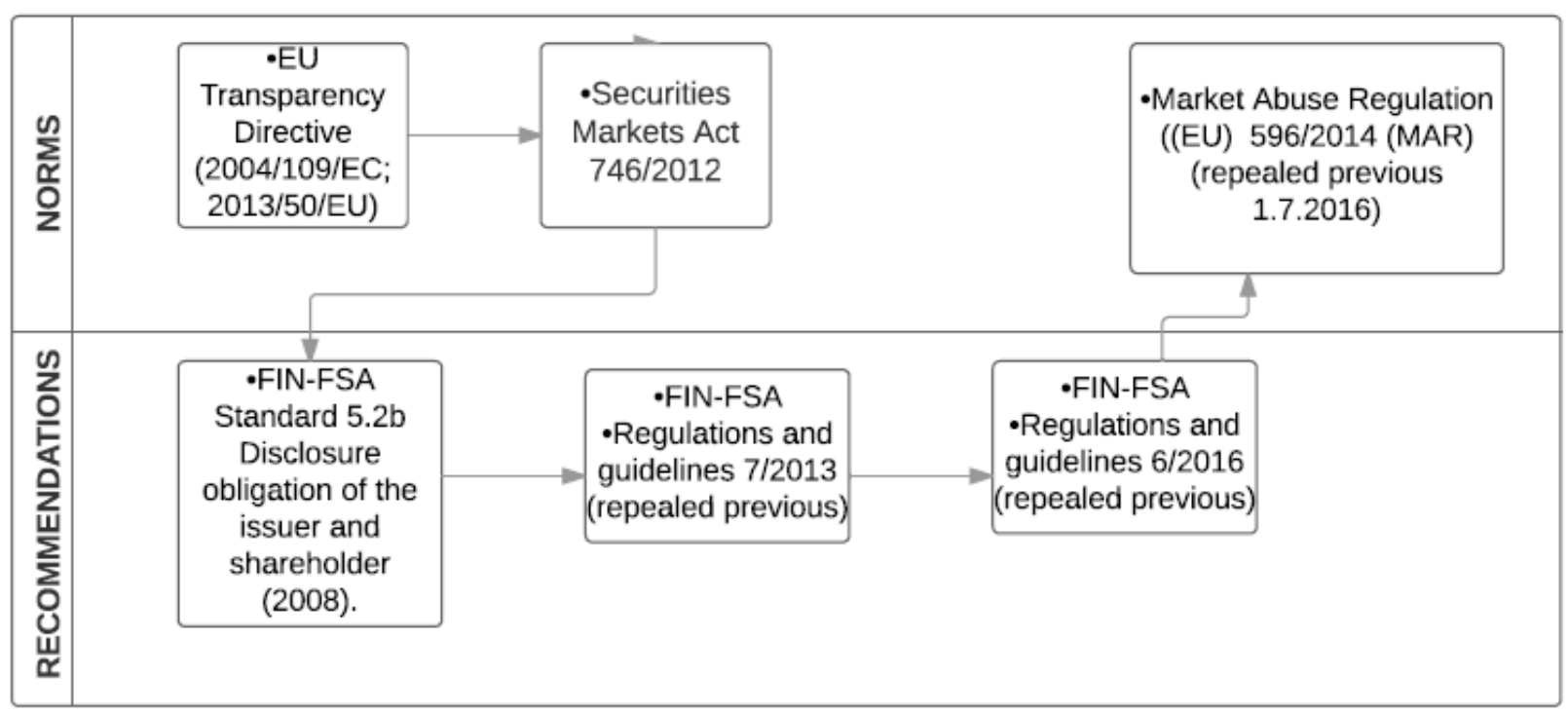

Figure 1. The regulatory background of disclosure policy documents in Finland (2006-2016)

Initially, a disclosure policy was introduced as a mandatory requirement by the influential Supervisory Authority standard 5.2b (valid 2008-2013). The standard included a binding norm stating that companies shall without undue delay publish all information that is likely to affect 
the value of the security (Financial Supervisory Authority, 2008, p. 13-14). The norm was accompanied by an application guideline recommending that companies should follow a consistent and transparent communication policy for the benefit of investors, as well as an application example illustrating the kinds of matters that a communication policy should contain. These included e.g. stating the purpose of investor relations, naming who is responsible for what, and describing which internal procedures are followed in communication, in particular in crisis situations. In 2013, the standard was repealed, and new guidelines were published (Financial Supervisory Authority, 2013c). Also the new Regulations and guidelines included the recommendation that companies "should define their operating principles and procedures for communication with the capital markets", and formalize them in a written disclosure policy (Financial Supervisory Authority, 2013c, p. 3). The recommended content remained the same as earlier (see Table 1, text marked with italics).

The 2013 Regulations and guidelines were repealed by new Regulations and guidelines in the spring 2016 (6/2016), and the recommendation of a disclosure policy had been removed from the new version. Soon after, these guidelines were further repealed in July 1st, 2016, when the EU Market Abuse Regulation (EU 596/2014/MAR) took effect. However, publishing a disclosure policy is considered a good practice, and it is still recommended on the Financial Supervisory Authority's (2013a) website and by the Nasdaq Helsinki Ltd (2016) (see Table 1). This historical background makes disclosure policy a particularly interesting example of the emergence, and potentially also disappearance, of policy genres in financial communication. It also illustrates how international regulation at EU level may affect national regulations and change the roles and dynamics between different normative sources. 
Table 1. Recommendations for drafting disclosure policies

\begin{tabular}{|l|l|}
\hline Financial Supervisory Authority (2013a) & Nasdaq Helsinki Ltd (2016) \\
\hline $\begin{array}{l}\text { FIN-FSA recommends that listed companies } \\
\text { define their principles concerning the disclosure }\end{array}$ & $\begin{array}{l}\text { To ensure that the company provides the market } \\
\text { with timely, reliable, accurate and up-to-date } \\
\text { obligation in the form of a disclosure policy. Such } \\
\text { information, the exchange encourages the company }\end{array}$ \\
$\begin{array}{l}\text { a policy paper consists of documenting the rules } \\
\text { according to which a company communicates }\end{array}$ & $\begin{array}{l}\text { to adopt an information and disclosure policy. A } \\
\text { company's information and disclosure policy is a } \\
\text { with the capital markets. It is important that this } \\
\text { document that helps the company to continuously }\end{array}$ \\
$\begin{array}{l}\text { sort of policy document be drafted at the time the } \\
\text { company is planning for listing. In its disclosure }\end{array}$ & $\begin{array}{l}\text { provide high-quality internal and external } \\
\text { information. It should be formulated in such a }\end{array}$ \\
policy, the company identifies those responsible & manner that compliance with it is not dependent on \\
for investor relations, the way the company's & a single person, and it should also be designed to fit \\
future prospects are discussed, the type of & the circumstances pertaining to the specific \\
guidance given to the markets, the circumstances & company. The information provided to the stock \\
under which a profit warning must be issued and, & market shall be correct, relevant, and reliable and \\
for example, what material information that must & shall be provided in accordance with the rules of \\
be disclosed under the Securities Markets Act & the Exchange. \\
generally means for the company. Besides the & \\
executive management, it is worthwhile for the & \\
board of directors to go through these matters. & \\
\end{tabular}

The instructions by the Nasdaq Helsinki stock exchange (2016, see Table 1) recommend that companies publish what they call an information and disclosure policy. It also expressly requires that each company shape the policy according to its own strategy. The purpose of this recommendation is probably to encourage companies to use the policies as substantive documents rather than symbolic ones (Stevens et al., 2005), so as to prevent them from being used in the service of nominal transparency. The requirement to consider company-specific circumstances also increases the need to reflect on the needs of shareholders and investors instead of only presenting an ideal image of transparency. From the point of view of genre theory, the disclosure policy texts of each company are instantiations the disclosure policy genre. Genre analysis is therefore useful as it helps to detect textual regularities and irregularities and to explain them. 


\section{Research design}

This paper focuses on the role of disclosure policy as a genre when listed companies strive to present themselves as transparent and reliable on their IR websites. As stated above, the disclosure policy outlines how a company defines its IR communication strategies and practices. Because the notion of transparency is rather vague and has different meanings for different audiences, it is interesting to see how it is understood and interpreted by companies in a genre devoted to meeting the general requirements of transparency. Making use of the genre is also practical because genres are ways of doing things, that is, disclosure policy documents are "doing transparency", and as the disclosure policy gathers relevant statements about the issue in one place, it makes it easier for the audience to find those statements, evaluate them, and engage in dialogue.

The aim of this paper is to discuss how transparency is communicated through the disclosure policy genre. The research questions are:

1. What are the rhetorical moves and steps that are present in disclosure policies and how consistent are they across the data?

2. How are the principles of financial communication described, and what is their relation to characterizations presented in authoritative documents, such as recommendations and guidelines?

The first research question is based on the assumption that the structural patterning of disclosure policies rhetorically supports the claimed transparency, and a description of the moves structure 
reveals which structures are considered to form an effective response to current transparency requirements. This part of the analysis covers the disclosure policy texts as a whole.

The second question focuses on the intertextual character of policies, which may show the degree to which transparency descriptions are company-specific. This is important because it might reveal a difference between substantive and symbolic policies (see Stevens et al., 2005). The requirement of contextual embedding is also emphasized in the stock market rules (see Table 1 above; Nasdaq Helsinki Ltd 2016). This part of the analysis covers the first three moves in the policy texts. This choice is based on their intertextual character: these moves contain explicit characterizations of transparency, i.e. descriptions of types of information and ways of giving it, which are also described in the recommendations and guidelines.

\section{Data}

The data of this paper focuses on the OMXHelsinki25 list, that is, the national listing of the 25 best performing and most traded companies published by the Nasdaq Helsinki stock exchange in November 2015 (OMXHelsinki25). The data has been gathered from the IR-related websites of these companies. The national listing has been chosen as the basis for data selection to enable potential comparisons with other countries later on.

Of the 25 companies on the listing, 13 companies had a document called a disclosure policy on their websites at the time of the data gathering. These companies are listed in Table 2. According to a survey conducted by the Finnish Financial Supervisory Authority (2013b) based on all companies at Helsinki Stock Exchange (125 companies, 1.7.2013), 38\% (48 companies) had 
published a disclosure policy on their websites, while $62 \%$ (77 companies) had not. The finding that $52 \%$ of the companies in the OMXHelsinki25 listing have a disclosure policy document may reflect a development in time (2013 to 2015) or alternatively, the need for the best performing and most traded companies to explicitly signal their transparency to the market.

Most of the disclosure policy documents were provided as PDF files accompanied by an introductory web text with the most important highlights of the longer document, while some were directly placed on the website without a PDF version. The names of the companies, forms of presentation of the document, and approximate number of words (approximate because some PDF files included paratextual features such as page headings, dates, and signatures that were included in the numbers, while others did not) are presented in Table 2.

Table 2. Forms of presentation and number of words of disclosure policy documents in the data.

\begin{tabular}{|l|c|l|c|r|}
\hline & $\begin{array}{l}\text { Introduct } \\
\text { ory web } \\
\text { text }\end{array}$ & Pdf & $\begin{array}{l}\text { Directly on } \\
\text { website }\end{array}$ & $\begin{array}{l}\text { No of words in whole } \\
\text { documents (including } \\
\text { paratextual material) }\end{array}$ \\
\hline 1. Neste Oil & Yes & Yes & No & 2,826 \\
\hline 2. Stora Enso & Yes & Yes & No & 2,246 \\
\hline 3. UPM-Kymmene & Yes & Yes & No & 757 \\
\hline 4. Outokumpu & Yes & Yes & No & 1,363 \\
\hline 5. Fortum & No & Yes & No & 1,688 \\
\hline 6. Sampo & Yes & Yes & No & 1,664 \\
\hline 7. Wärtsilä & Yes & Yes & No & 2,322 \\
\hline 8. Metso & No & Yes & No & 1,928 \\
\hline 9. Cargotec & Yes & Yes & No & 1,458 \\
\hline 10. Elisa & Yes & Yes & No & 1,280 \\
\hline 11. Orion & No & No & Yes & 694 \\
\hline 12. Valmet & No & No & Yes & 1,898 \\
\hline 13. YIT & No & No & Yes & $\mathbf{2 1 , 4 6 9}$ \\
\hline Total (Yes) & $\mathbf{8}$ & $\mathbf{1 0}$ & $\mathbf{3}$ & \\
\hline
\end{tabular}


At the time of data gathering, nine of the 25 top companies on the OMXHelsinki25 list did not have a disclosure policy document publicly available on their IR website (Huhtamäki, Kemira, Kone, Konecranes, Nokia, Nokian renkaat, Nordea, Teliasonera, Tieto), and one announced that they had one but it was not public (Outotec). In addition, two companies (Kesko, Amer Sports) had a very short (about 200 words) document under the titles IR principles and Communications policy, respectively, which have been excluded from the analysis because they might represent a different genre.

As we are dealing with digital data, the websites are actively updated, and the situation keeps changing, which is why the documents have been copied into a word file and analyzed independently of the website context in question. The data consist of about 21,000 words; the average disclosure policy length is a little over 1,600 words (see Table 2). However, as indicated in Table 2, the length of disclosure policy texts varies from about 700 words (Orion, UPMKymmene) to over 2,000 words (NesteOil, StoraEnso, Wärtsilä). The length of the texts may reflect the intended readership: the short texts seem to address external audiences while the longer ones include many details that are mainly relevant for employees (see also Koskela \& Kuronen, 2014).

\section{Method}

This research applies a move analysis to answer to the first research question as described above, that is in order to quantitatively and qualitatively describe the overall rhetorical structure of the disclosure policy documents and to discuss how it is used rhetorically to support the claimed 
transparency (see Swales, 1981; 1990). The analysis applies the procedure of corpus-based move analysis described by Upton and Cohen (2009).

Table 3. Application of Upton and Cohen's analysis procedure in this research.

\begin{tabular}{|c|c|}
\hline $\begin{array}{l}\text { Analysis procedure of Upton \& Cohen } \\
(2009, \text { p. 589) }\end{array}$ & Analysis procedure reported in this paper \\
\hline $\begin{array}{l}\text { 1. Communicative/ functional categories: Develop the } \\
\text { analytical framework: determine set of possible functional } \\
\text { types of discourse units, that is, the major communicative } \\
\text { functions that discourse units can serve in corpus }\end{array}$ & $\begin{array}{l}\text { 1. A set of possible functional types of discourse units was } \\
\text { determined: the rhetorical function of each text segment was } \\
\text { identified; pilot coding was carried out leading to a coding } \\
\text { protocol with definitions of potential moves. }\end{array}$ \\
\hline $\begin{array}{l}\text { 2. Segmentation: Segment each text into discourse units } \\
\text { (applying the analytical framework from Step 1) }\end{array}$ & $\begin{array}{l}\text { 2. The whole data was segmented in discourse units with a } \\
\text { rhetorical function. The coding protocol was revised, new } \\
\text { potential moves were identified. }\end{array}$ \\
\hline $\begin{array}{l}\text { 3. Classification: Identify the functional type of each discourse } \\
\text { unit in each text of the corpus (applying the analytical } \\
\text { framework from Step 1) }\end{array}$ & $\begin{array}{l}\text { 3. The discourse units in the relevant sections of the texts } \\
\text { were classified into functional categories, i.e. rhetorical move } \\
\text { types. All potential moves were classified by move type, and } \\
\text { compared with lists of recommended content. }\end{array}$ \\
\hline $\begin{array}{l}\text { 4. Linguistic analysis of each unit: Analyze the } \\
\text { lexical/grammatical characteristics of each discourse unit in } \\
\text { each text of the corpus }\end{array}$ & $\begin{array}{l}\text { 4. Linguistic analysis: } \\
\text { The first three moves were chosen as objects of a detailed } \\
\text { linguistic analysis because they were identified as prominent } \\
\text { with respect to explicit descriptions of transparency. } \\
\text { A linguistic analysis of the three rhetorical moves } \\
\text { dominating the beginning of the texts was carried out. }\end{array}$ \\
\hline $\begin{array}{l}\text { 5. Linguistic description of discourse categories: } \\
\text { Describe the typical linguistic characteristics of each } \\
\text { functional category, based on analysis of all discourse } \\
\text { units of a particular functional type in the corpus }\end{array}$ & $\begin{array}{l}\text { 5. Move } 3 \text { was chosen for a closer intertextual analysis } \\
\text { because it contains explicit characterizations of transparency, } \\
\text { i.e. descriptions of types of information and ways of giving it. } \\
\text { An intertextual comparative semantic analysis was carried } \\
\text { out: the variation of characterizations and their uniqueness was } \\
\text { analysed with respect to regulatory texts. }\end{array}$ \\
\hline $\begin{array}{l}\text { 6. Text structure: Analyze complete texts as sequences of } \\
\text { discourse units shifting among the different functional types }\end{array}$ & $\begin{array}{l}\text { 6. Not applied. The order of moves and how they construct } \\
\text { texts is a subject for future research. }\end{array}$ \\
\hline $\begin{array}{l}\text { 7. Discourse organizational tendencies: Describe the general } \\
\text { patterns of discourse organization across all texts in the corpus }\end{array}$ & $\begin{array}{l}\text { 7. Comparisons between companies were carried out in all } \\
\text { phases. }\end{array}$ \\
\hline
\end{tabular}

After establishing that disclosure policy can be called a genre in its own right, the first phase of move analysis was to determine the rhetorical purpose of the genre (Upton \& Cohen, 2009, p. 592). This was specified in an earlier study by Koskela and Kuronen (2014) concluding that the expressly stated rhetorical purpose of the disclosure policy genre is to convince investors, shareholders, analysts, media and the general public of the transparency of the company by explicating the principles the company follows in its financial communication. However, a 
disclosure policy document can be described as having mixed motives, because it addresses both an internal and external audience (Koskela \& Kuronen, 2014; Guimard, 2008).

The next phases of the analysis are described in detail Table 3. In line with the guidelines established by Upton and Cohen (2009, p. 589, 592), the analysis of the moves was conducted through an iterative process where the rhetorical function of each text segment was first identified and then checked against each text. In this way a preliminary list of moves was defined that was then checked against the whole data and constantly refined and redefined. This procedure was continued to the point of data saturation, as indicated by no new categories emerging. For the purpose of this analysis, a move was defined as a constituent part of a genre that typically characterizes texts in a particular genre. Moves often appear in a fixed order but are non-hierarchical, show little variation between texts representing the same genre, and tend to form larger patterns (Swales, 1981; Dudley-Evans, 1986). Consequently, a move in this analysis is understood as a rhetorical component having a communicative function. In order to be registered as a move, a constituent part has to be present in at least four of the documents studied.

In order to answer to the first research question, the analysis of rhetorical moves has been carried out on the full length of all the texts in the data even though the texts have different length. The results are presented in Table 4. In order to answer to the second research question, the data was limited to the introduction parts of the disclosure policy texts containing the first three moves. These moves can be considered constitutive of the genre because they seem to be shared by most of the texts in the data, and they contain explicit descriptions of how the companies understand 
and interpret transparency. It is typical of established genres to begin with a recognizable structural pattern. In fact, genre analysis originally looked at the introduction sections of academic articles (Swales, 1990), and concentrating on the beginning of texts remains a common choice in the analysis of rhetorical moves (see e.g. Chiu, 2016). The number of words in the text passages studied in this part, consist of about 300 words in each text, altogether about 4000 words.

In the analysis intertextuality is understood broadly as the presence of text in another text (Fairclough, 1992, 2003; Bhatia, 2010). Accordingly, intertextuality will be addressed as located at the textual level and covering how a text refers to other prior texts, in the sense of the borrowing, mixing and embedding of resources across texts (Koskela 2013, p. 391-392). The analysis pays particular attention to unmarked intertextuality, also called interdiscursivity, in the form of recognizable phrasing, terminology, and echoing certain ways of communicating (cf. Bazerman, 2004; Bhatia, 2010, p. 35-36). In order to identify the potential embedded interdiscursive features, central resources from immediately relevant intertexts was listed as shown in Appendix 1. The list does not claim to be exhaustive, and consists of linguistic descriptions defining the recommended types of information and ways of delivering it as described in the Securities Markets Act, by Nasdaq OMX Helsinki, and Financial Supervisory Authority (see Figure 1 above). These lists offer a point of comparison for the analysis of variation and uniqueness of transparency descriptions. In other words, the analysis will illustrate the role of intertextual influence of laws, rules, and recommendations as well as the companyspecific interpretations of transparency. 
In the next section, the first research question will be answered as the analysis of the rhetorical moves in the disclosure policy texts will be presented. Deciding on a descriptive name for rhetorical moves requires a detailed analysis, which is why the names of moves in Table 4 are preliminary. After that the second research question will be addressed through the more detailed linguistic and intertextual analysis of the three first moves.

\section{Results}

The rhetorical moves structure of all disclosure policies (13) in the data can be divided into three parts: introduction, practices (how, what, what if, who) and technical details (see Table 4). All texts have an introduction where goals and objectives, norms and principles are described. After that, company practices are explained with different levels of detail and in varying order. Therefore, also the rhetorical moves appear to be less standardized and more applied to the company context. Moves that are present in most policies include information on communication channels (12 companies), silent period (also called closed period or closed window, 13; companies), dealing with rumors (12 companies) and communicating during crisis or in other exceptional situations (10 companies).

Table 4. Moves structure of Finnish disclosure policy documents

\begin{tabular}{|l|l|}
\hline Introduction & Practices (what if) \\
\hline Aim, goal, objectives & Profit warnings* \\
\hline Norms followed & Rumors and leaks \\
\hline Communication principles & Crisis communication \\
\hline & \\
\hline Practices (how) & Practices (who) \\
\hline Contacts with investors, meetings & Spokespersons \\
\hline Communication channels & Roles and responsibilities* \\
\hline Releases & Insider information \\
\hline & \\
\hline Practices (what) & Technical \\
\hline Material/ price sensitive information* & Language \\
\hline Financial information & Review and update \\
\hline
\end{tabular}




\begin{tabular}{|l|l|} 
Guidance/Outlook/Prospects* & \\
\hline Silent period/Closed window & \\
\hline Changes in shareholdings & \\
\hline Content recommended by authorities marked with * \\
\hline
\end{tabular}

When compared with the content recommended by the authorities, marked with a star $(*)$ in Table 4, it becomes evident that not all of the companies include these aspects in their policies. Only 6 companies of 13 report on how they interpret price sensitive or material information, 8 companies clarify the roles and responsibilities in Investor Relations, and 9 describe the ways of discussing future prospects and giving guidance. This result shows that the suggestions of content are understood as recommendations and not as binding norms, and demonstrate the company-specific character of the policies. Of the best-practice recommendations listed by Guimard (2008, p. 151), information of what, when and how often the company communicates with the markets and when they do not, are included with differing levels of detail in the moves Releases (included by 8 companies), Financial information (8 companies), and Silent period (13 companies), but do not form specific rhetorical moves. Based on these results, the disclosure policies seem to be more substantial than symbolic texts (see Stevens et al., 2005).

Of the rhetorical moves typical of the strategy genre presented by Cornut et al. (2012), priorities and goals occur also in disclosure policies. Similarly, in public sector communication policies studied by Grove Ditlevsen and Kastberg (2007), there is a corresponding shared content element principles, values, visions, and goals (2007). This is logical, as setting the objectives is a key element of strategy texts, and it has different scope in different types of strategy texts. While corporate strategies state the organization's broad objectives, communication policies set the goals for communication in general, and disclosure policies concentrate on the goals for Investor 
Relations communication. In its different forms, this rhetorical move is a natural starting point for strategy texts. The same applies to a description of responsibilities, which is present in corporate strategy texts and in disclosure policy texts (see Cornut et al., 2012, p. 39). This rhetorical move seems to be a key element in what Steyn (2000) calls functional strategies with a status below corporate level strategy but above operational level strategies. However, a common rhetorical move $(56 \%)$ in corporate strategies, the process of drafting the strategy, is not included in disclosure policies. According to Cornut et al. (2012, p. 40) the communicative purpose of this move is to show how the organization accommodates different interests, but also to demonstrate professionalism. In disclosure policies, both these purposes are present, but met by other rhetorical means.

All in all, the analysis of rhetorical moves in the whole documents indicates that the introduction part is more standardized than the rest of the documents. In this part, explicit characterizations of transparency are presented, in particular in the third move Communication principles. Therefore, a more detailed linguistic analysis of the introduction part and especially the third move is presented below.

\section{Rhetorical moves in the introduction part}

As Table 4 illustrates, the introduction part of the disclosure policy texts (DP) in the data is characterized by three distinct rhetorical moves preliminary named aims, goals and objectives, norms followed and communication principles in Table 4. Based on a more detailed analysis, these moves will be named more descriptively as follows: describing the aim of the document (Move 1), listing the relevant laws and norms and stating that the company follows them in its IR 
practice (Move 2), and explicating the principles that the company follows in its communications with the market (Move 3). The following extract from UPM-Kymmene Corporation's disclosure policy illustrates a typical disclosure policy beginning (example 1).

Example 1: A typical beginning of a disclosure policy.

\section{UPM-Kymmene Corporation}

The Board of UPM-Kymmene Corporation has approved the Disclosure policy on 24 July 2008.

\section{DISCLOSURE POLICY}

Move 1: aim of document

The purpose of UPM-Kymmene Corporation's disclosure policy is to guarantee fair disclosure of information to the public and to make sure that disclosure is timely and consistent at all levels.

\section{Legal obligations}

Move 2: statement of compliance

As a listed company, UPM complies with the requirements of Finland's Securities Markets Act and with the rules of NASDAQ OMX Helsinki Ltd.

\section{Disclosure principles and compliance}

Move 3: explicating principles

The Company's external reporting follows the principle of providing accurate and complete information in a timely manner and non-selectively to all parties in the market. Any information disclosed must be correct, relevant and clear, and it must not be misleading. Information must be released promptly.

From stating the aim of the text to declaring compliance

Before turning to the third move in more detail, I will briefly describe the two others. Move 1 can be described as metatextual as it explains to the reader what the document is about. Consequently, the move is intended to be understood as an explicit statement of the goal or purpose of the document. However, as Catenaccio (2008, p. 13) notes, such declared communicative purposes should not be taken at face value because the authors might have other communicative purposes that they are less open about. In 10 of the 13 analyzed policies, this move describes what the policy document does, thus presenting the document as an active actor 
as in example 2, while in one document the move states what the purpose of the document is (the purpose of DP is to guarantee fair disclosure, see example 1 above).

Move 1 is typically intertextual as it echoes the phrases used in the standard (5.2b) published by the Finnish Financial Supervisory Authority (e.g. 2008) recommending that companies should formulate and publish a disclosure policy. Example 2 illustrates how the reference to the authoritative text is normally unmarked, as if expecting the intended readers to recognize the wording based on their expertise; (cf. "Issuers should define their operating principles and procedures for communication with the capital markets." [Financial Supervisory Authority, 2008]). The two documents in the data lacking this move have replaced it by stating what the DP emphasizes (StoraEnso) or what the goal of Investor Relations is (Metso) giving it a somewhat different tone, which relies less on the authoritative voice and more on the companies' own active role.

Example 2: Echoing the wording of normative sources

This policy describes the main principles on how Outokumpu communicates with the capital markets and discloses share price sensitive information to its stakeholders.

In summary, Move 1 is an established part of a disclosure policy document with only a minor variation in the rhetorical structure. The rhetorical function of the move is to declare the openness and transparency of disclosure. To achieve this, most companies use similar type of wording, reflecting the reciprocity between language-in-use and social practices (see Ohlsson, 2011). However, the disclosure policy documents seem to be sharing knowledge that the potential readers of disclosure policies already know. Because the readers are likely in the most part to be experts who are familiar with the genre, relevant legislation and recommendations, 
stating the purpose of the document seems to have some other function than purely being informative. Generally, genre affiliation of a text is signaled contextually, for example, in a section title or a document heading, thus orienting the reader to recognize the genre and read it as such. Such signaling of genre is also a feature of disclosure policies as they are often introduced by a text on the website and may require the reader to open a pdf file with the genre name in its title. Consequently, it seems that Move 1 serves a rhetorical or ritualistic function.

$\underline{\text { Move } 2}$ which declares that the company follows relevant legislation can be called a statement of compliance. The function of this move seems to be mainly to assert that the company knows the law and follows it and thus explicitly declare awareness of transparency issues. It seems to serve a similar communicative purpose of demonstrating rigour and professionalism as descriptions of the strategy planning process in corporate strategies (Cornut et al., 2012). In example 1 above, UPM lists its legal obligations immediately after Move 1, which enables Move 2 to be read as a motivation for publishing a disclosure policy (being a listed company, UPM is obliged by the rules and recommendations to publish a disclosure policy). Example 3 is the opening sentence of Metso's disclosure policy. The policy starts with the statement of compliance before turning to the principles followed by the company, ways of communicating, and type of information presented, in that order.

Example 3: Statement of compliance in opening sentence

In its communications, Metso complies with Finnish and EU legislation, NASDAQ OMX Helsinki Ltd.'s regulations, the guidelines of the Finnish Financial Supervisory Authority, and the company's corporate governance principles. 
From a Finnish perspective, in a country known as one of the least corrupted in the world (Transparency International, 2015), these statements can be viewed as redundant because they equate to saying the firm will follow the law rather than breaking it. The data reveal the move to be present in only seven policies (those of NesteOil, StoraEnso, Metso, Elisa, Orion, Cargotec, Valmet) of the possible 13. That proportion is still rather high because the move is not explicitly mentioned by any authority or the stock market. However, it seems to be present in international contexts, for example in the Xerox disclosure policy (Xerox 2001/2008). For international investors, this move includes relevant information as it declares that it is Finnish legislation that is followed by the company and not that of some other jurisdiction. Nevertheless, the statement may be read as an answer to a hidden or unspoken argument or presupposition. It therefore seems that while Move 2 may have an informative function for some readers it concentrates more on performing a persuasive function, an attestation of transparency awareness, which might explain its absence from six of 13 policies.

Move 3 explicating the principles that the company follows in its communications with the market constitutes the rationale of the whole genre, because it is the place where the companies expressly state how they communicate with the capital markets and simultaneously present their understanding of transparency. This constitutive move will be studied in both quantitatively and qualitatively below. 
Principles for communicating with the capital markets

As illustrated by example (1) above, Move 3 declares the express communicative purpose of the genre. The rationale and task of a disclosure policy is described for example on the Finnish Financial Supervisory Authority (2013a) website as follows:

FIN-FSA recommends that listed companies define their principles concerning the disclosure obligation in the form of a disclosure policy.

The results of the analysis indicate that this move typically consists of three steps. Essentially the companies may present a list of principles they claim to follow (1), they may characterize the particular ways and means the company uses to communicate (2), and/or they may describe the type of information the company publishes (3). As is typical of the step structure of rhetorical moves, different combinations of these steps are evident in the data. The steps may also be embedded or overlap to some extent (see e.g., Chiu 2016, p. 56).

In total, six companies of the 13 firms examined included all the above steps in the move. The step of listing principles is used by nine of the 13 companies, describing what the information given is like by 12 of the 13 companies, and describing how the information is given by 10 of the 13 companies. Example (1) above illustrates how the steps together structure Move 3.

The main intertextual inspiration for Move 3 comes from both repealed and valid authoritative documents. Although the formulations used in authoritative texts are repeated frequently in the data, there is considerable variation in the descriptions demonstrating the company-specific character that the document should have (Nasdaq Helsinki Ltd 2016; Table 1 above). A rigorous and variable use of abstract nouns (such as accuracy, consistency, and proactivity) as well as adjectives (such as coherent, essential, and up-to-date) and adverbs (such as actively, fairly, and 
promptly) in the data indicates that the companies have carefully considered how to convince the market of the reliability of the company. Thus, the analysis below illustrates how Finnish companies interpret the core ideas of transparency for their own communication and how they claim to put those core ideas into practice in their IR communication.

\section{Listing principles}

In order to attain the communicative purpose of the disclosure policy genre, that is, to define the principles and methods that a company follows in its communications with the capital markets, nine of the 13 companies chose to offer a list of principles. In total, such lists itemize 21 different principles with 36 mentions. The companies seem to trust in lists and see them as rhetorically efficient: one company listed as many as six principles, while five companies listed five principles, and one company stated four principles. The principles most often listed are honesty, openness, and transparency (three companies). Interestingly, honesty and openness are referred to by Albu and Wehmeier (2014, p. 118) as simplistic definitions of transparency. In examples 4 and 5, Orion and Stora Enso both list five principles with no overlaps.

Example 4: A list of five principles of communication by Orion

The key principles in Orion's communications are openness, impartiality, reliability, simultaneousness and consistency.

Example 5: A list of five principles of communication by Stora Enso Group

The Disclosure Policy of the Stora Enso Group emphasises the importance of transparency, credibility, responsibility, proactivity and interaction.

These long lists tend to resort to abstract expressions, but principles can be described in more concrete ways, as illustrated by example 1 above in which UPM states that it follows the 
principle of providing accurate and complete information, and Fortum indirectly lists types of communication as outcomes of following company principles (example 6).

Example 6: Types of communication related to principles by Fortum

According to Fortum's principles, the company's communication is:

- Proactive and transparent

- Relevant, consistent and understandable

- Timely and equal

In Figure 2, all the principles named in the 13 policies studied are listed, even those expressed in more concrete ways (e.g., accurate and complete= accuracy and completeness).

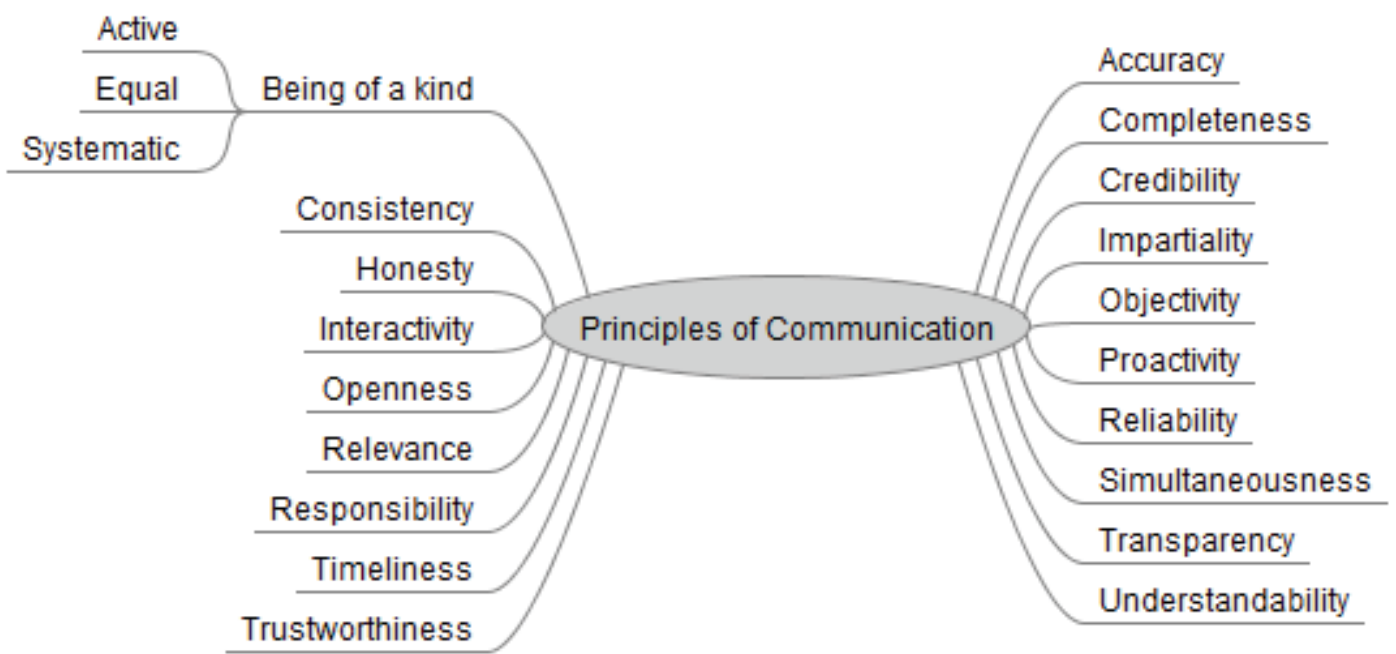

Figure 2. Principles of financial communication in the data

One important motivation for listing abstract principles is that the lists fulfill the legal requirement of being open about the firm's principles. The list can be seen as a direct answer to the requirement of defining the operating principles and methods according to which the companies communicate with the capital markets. The principles listed are mainly positive, thus 
avoiding a mention of the downside of transparency (see Hansen et al., 2015, 120). As the lists of principles differ from company to company, which may intertextually reflect comparable formulations in other documents; they are intended to convince readers of the earnest intentions of the company, but also of its expertise, leadership skills, and preferred forms of management (see also Cornut et al., 2012). Mainly, however, a list of abstract principles serves the purpose of persuading readers of the good character of the company through positive language, which is a common feature of strategy texts in general (see Vaara et al., 2010), but especially important in delivering a positive image of the company in terms of transparency.

Although there is considerable variation, there are clear interdiscursive connections to legislation, recommendations, and standards, even if those do not directly list required characterizations. Conceptually, it is interesting to note that companies consider transparency as a principle alongside others like openness and trustworthiness. In earlier research, openness has been seen as a characteristic of a company, while transparency would require a dialogue with the stakeholders to ensure that the messages are understood (Albu \& Wehmeier, 2014, pp. 99, 119). As a whole, the principles listed include both such characteristics that the companies alone can answer for (simultaneousness, honesty, timeliness) but also those requiring involvement of shareholders, investors, analysts, and other stakeholders (interaction, but also credibility and understandability). However, it is clear that many companies seem to be well aware of what type of transparency would be ideal for their intended audience, and try to take them into consideration in their policy texts. They seem to understand the value of dialogue and interaction even though they may not necessarily live up to the ideal in practice (Hansen et al., 2015, p. 120). 


\section{Describing what the information given is like}

In much the same way as firms list the principles they adhere to, they describe the type of information they produce. These descriptions of information quality are here interpreted as step 2 of Move 3. Describing the quality of information can also be traced back to guidelines and recommendations. A brief look at these authoritative documents indeed reveals a strong focus on characterizing the type of information that is required (see e.g. Table 1 above). This suggests that the concept of transparency in the normative documents tends to be interpreted as information giving and availability (see Albu \& Wehmeier, 2014, p. 118). However, the characterizations of the required information type can also be extended to include how the information should be given (e.g., clear information vs. information given clearly).

There are 20 different descriptions of information quality in the data, and the firms offer up to seven descriptions each. Again the most descriptions are given by Orion (7), Fortum (6) and Neste Oil (5). These companies seem to be oriented toward structuring Move 3 in the form of lists. This structural similarity but different choices of characterizations may indicate mutual benchmarking and intentional differentiation (Koskela \& Kuronen, 2014, p. 197). The most often quoted quality descriptions are sufficient (8), and accurate (7), while the rest of the descriptions have between one and four mentions each. Figure 3 describes the labels for the quality of information listed in the data. The descriptions are typically adjectives placed as attributes of the word information. 


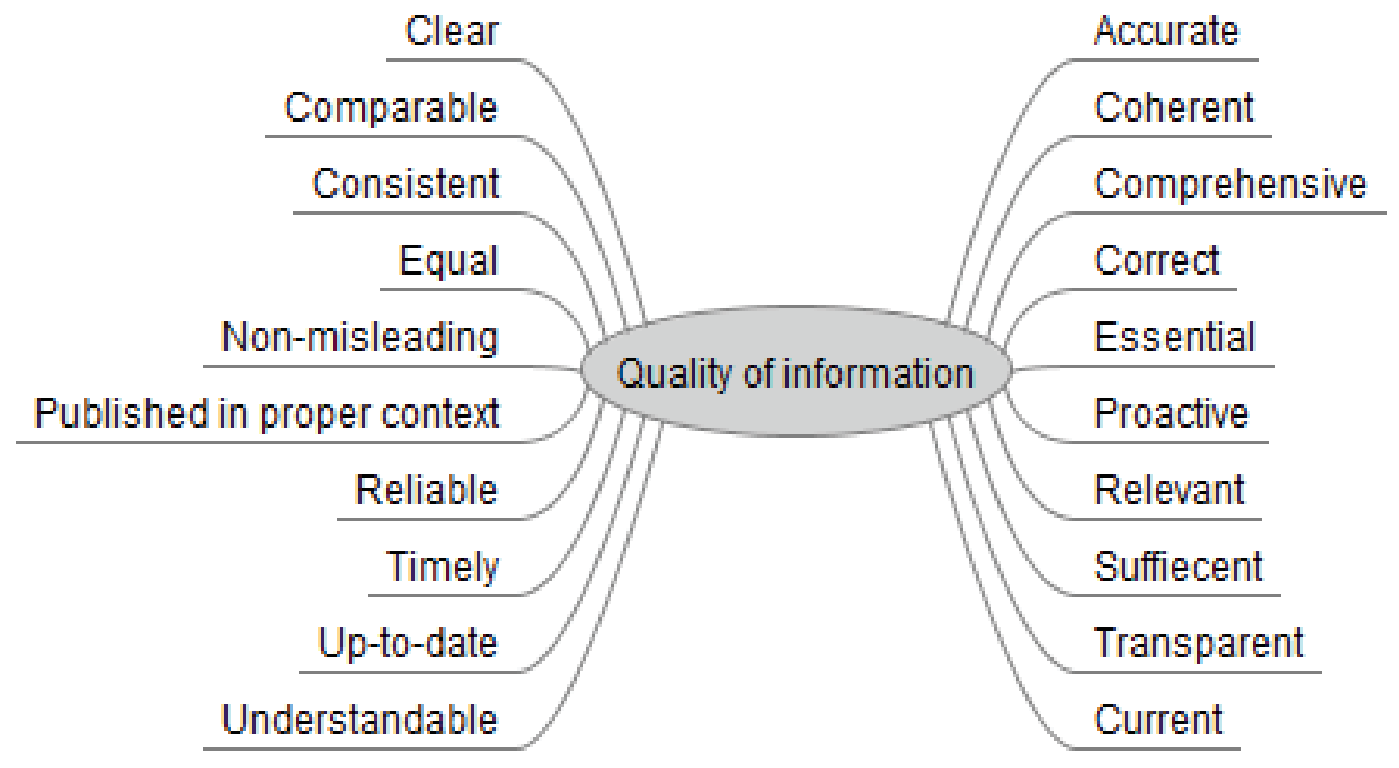

Figure 3. Quality of information as described in the data.

A comparison with the information quality characterizations in Appendix 1 reveals that 11 of the 20 characterizations in the data are based on authoritative texts, since they include recognizable phrasing and terminology. The intertextual bonds between the characterizations and earlier documents are therefore strong. However, there are also unique characteristics such as equal, proactive, and published in the proper context. The normative characterizations not included by the companies include high-quality, honest and neutral, that might be because they are either considered self-evident (e.g., high-quality) or too much to promise (e.g., neutral).

In examples 7 and 8, Orion and Metso list the type of information they claim to be giving. They also mention what the information is about and whom it is directed toward (company stakeholders vs. capital markets). 
Example 7: Type of information, intended audience and goal by Orion

The goal is to provide reliable, comprehensive, timely and comparable information about the company to stakeholders and present an image of Orion as a responsible and ethical company.

Example 8: Type of information, intended audience and topics by Metso The goal of Metso's Investor Relations is to support the correct valuation of Metso's share by communicating correct, sufficient, and relevant information to capital markets about Metso's operations, operating environment, strategy, objectives, and financial status.

Interestingly, both companies essentially quote guidelines and recommendations, which may create a less than engaged impression (see strategic vs. substantial documents above). Orion also exercises honesty and openness in practice when it declares that it intends to present a responsible and ethical image of the company. The communicative purpose of Orion's disclosure policy therefore tends toward external image construction. However, as Catenaccio (2008, p. 14) insightfully states, one should be careful with explicit declarations of communicative purposes because there are "differences between what a text purports to do, what it is perceived by the recipient as actually doing, and what it actually does."

\section{Describing how the information is given}

The third step constructing Move 3 consists of descriptions of the way in which information is given, or the manner of communicating. This step can again be traced back to the recommendations and legislation giving instructions on the ways companies are supposed to inform the market actors of their decisions and other relevant issues, which explains why this step is commonly found in disclosure policies (see Appendix 1). 
Analysis of the data shows that there are 15 different descriptions of the ways of giving information. One company can list up to six or seven descriptions, as Cargotec (6) and Outokumpu (7) decided to do. The most quoted descriptions are directly traceable to authoritative texts: for example, that information is given simultaneously (7) and without (undue) delay (6) are direct quotes from authoritative sources (Financial Supervisory Authority, 2013c, p. 13, 14). The descriptions used are presented in Figure 4.

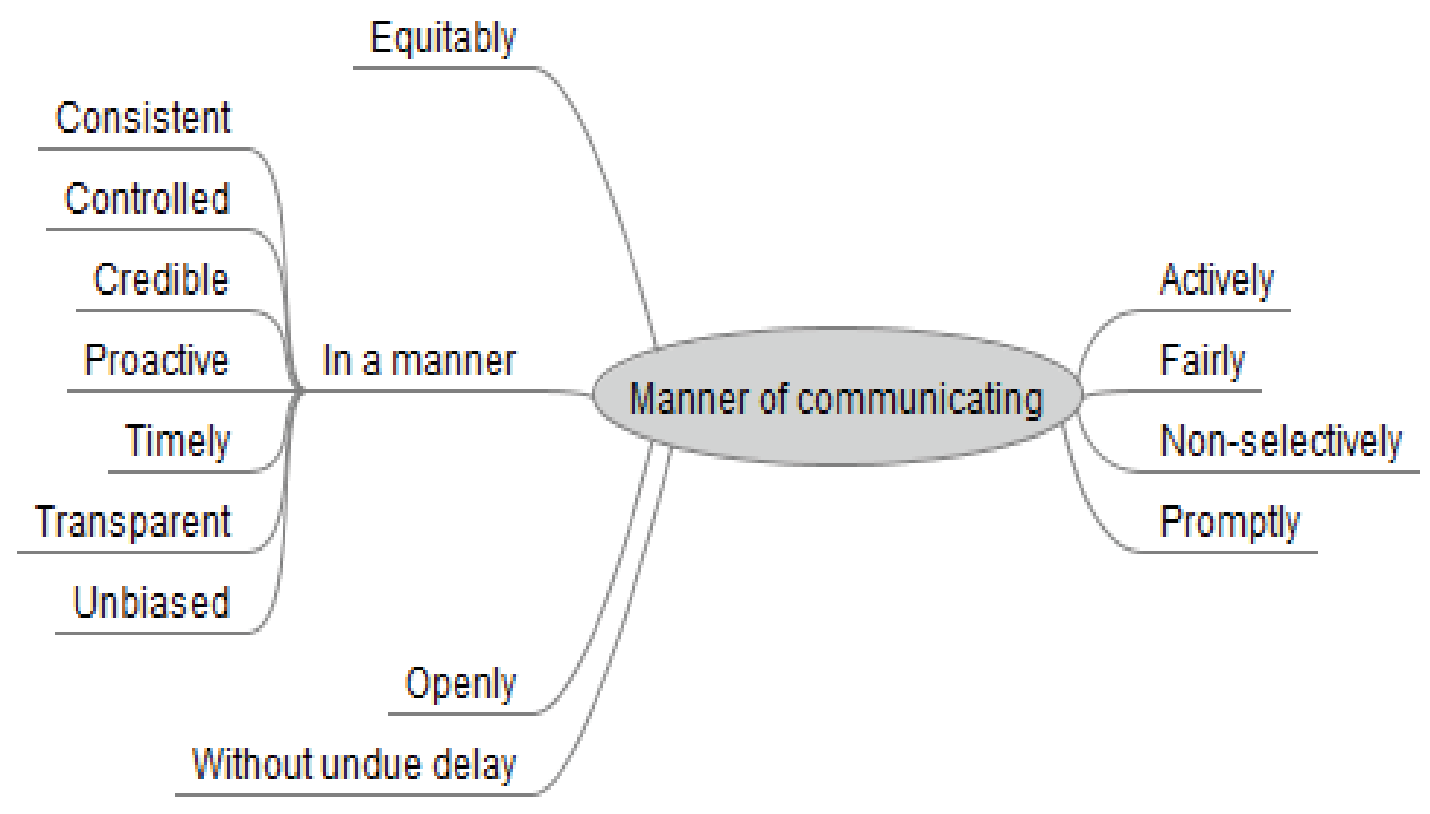

Figure 4. Descriptions of the manner of communicating.

Typical expressions include adverbs as well as the formula in a(an) $x$ manner. Examples 9 and 10 illustrate the intertextual nature of these descriptions.

Example 9: The manner of communicating by Outokumpu 
Outokumpu is committed to communicate actively and openly with all of its stakeholders. All communications are performed in a credible, proactive, unbiased and timely manner.

Example 10: The manner of communicating by Cargotec

Cargotec is committed to communicating actively and openly with all stakeholders irrespective of whether the information is positive or negative for the company. All communications are performed in a transparent, credible, proactive and consistent manner.

Both companies devote two sentences to the manner of communicating; the first being almost identical for both companies, with the exception that Cargotec has added a remark on both positive and negative information. The second sentence is also similar in structure and number of descriptions but differs in content: credible and proactive are shared descriptions while the two others in each (transparent, consistent, unbiased, timely) are company-specific. The structural and rhetorical similarities in texts representing the same genre result from the similarity in function, but may also indicate mutual benchmarking in a small market.

\section{Combinations of steps}

As is typical of the step structure of rhetorical moves, different combinations occur in the data. Examples 11 and 12 show how listing principles, characterizing the information given, and describing the manner of communicating can be combined.

Example 11: Combining the what and the how by Metso 
Metso communicates both positive and negative issues equally and simultaneously to all stakeholders, and aims to give a fair and correct view of the company's operations without undue delay.

Example 12: Combining the what and the how by Sampo Sampo consistently handles the aspects of its operations and publishes its positive and negative stock exchange releases without undue delay and makes them simultaneously available to all of its stakeholders.

In example 11, Metso combines the what with the how and even adds the goal of such actions. Similarly, Sampo embeds a characterization of the type of information in the description of the manner of communicating. Steps 2 and 3 can easily be combined, but are normally not mixed with listing principles, which is a more separate declaration probably because of its more abstract nature. These combinations show that the firms not only are familiar with the distinctive lexical features and the prototypical move structure of the disclosure policy genre, but are also able to bring in company-specific features according to the shared professional conventions.

\section{Discussion}

This paper has examined how transparency is communicated through the disclosure policy genre. The first research question concerned the moves structure and its consistency in the data. The results of the analysis show that the structural patterning of disclosure policy documents consists of rather consistent introduction sections, more variable descriptions of practices as well as some moves of a more technical nature. 
In the introduction section, there are three constitutive rhetorical moves of the disclosure policies that form the core of the policy. Move 1 can be described as metatextual as it explains to the reader what the document is about (see Catenaccio 2008, p. 13). This move is typically intertextual as it echoes the phrases used in a standard published by the Finnish financial authority.

Move 2, a statement of compliance, declares that the company adheres to the requirements of the relevant legislation. The rhetorical function of this move is to assert that the company knows the law and follows it, which according to Cornut et al. (2012, p. 41) fulfills an educational and legitimating function. Interestingly, this move is not required or mentioned in any of the authoritative documents but it is still rather common. For international investors, this move includes relevant information as it declares that it is Finnish legislation that governs the company. Nevertheless, being an answer to an unspoken argument or presupposition of unethical behavior, the statement is an example of how transparency practices implicitly bring up the antonyms of transparency (see Hansen et al., 2015, p. 120).

Move 3, in contrast, declares the stated communicative purpose of the genre by expressly describing the principles the companies claim to follow. Normally this move is realized through three steps. First, the companies present a list of abstract principles; second, they characterize the particular ways and means the company uses to communicate, and third, they describe the character of information the company publishes. As is typical of a step structure, these steps do not always occur separately and may overlap to some extent. 
The structural patterning of stating what the document is about, declaring compliance, and describing what type of information is disclosed and how is a rhetorically sound choice for a company. The consistent pattern makes it possible for firms reduce the ambiguous practice of representing transparency (Christensen \& Cheney, 2015, p. 78). This is the strength of an established genre. The approach enables companies to safely formulate their transparency claims as an answer to a question posed by the authorities, a step that is again rhetorically efficient. However, there is the risk that by following the pattern too closely may cause the company to give the impression it promotes only nominal transparency. This is particularly relevant in the case of companies adopting exactly the same wording, which indicates the presence of a template suggesting the texts.

Consequently, there is a tension between applying a consistent pattern and quoting regulations, and using company-specific formulations. In some cases, such formulations may not be fully developed yet, because the genre is relatively recent (stemming from 2008: see Koskela \& Kuronen, 2014). Alternatively, the document has not been considered important enough to merit the effort, or more practically, the firms may use the same consultancies to advise them on drafting their statements (see Guimard, 2008, p. 48-49). Instead of varying the form of the document, the companies use company-specific characterizations of the principles, types of information, and ways that information is offered, that is, in the descriptions of how they choose to interpret transparency.

The second research question focused on the ways in which the principles of financial communication described, and their intertextual connections. The results of the analysis show 
that there are about 20 different characterizations in each phase but that the intertextual connections to the law, rules, and recommendations remain strong. The sources of variation can be interpreted in two ways. If disclosure policy is mainly considered an answer to the requirements by authorities and thus becomes a carrier of nominal transparency, the differences between companies might be the result of negative benchmarking (e.g. Stevens et al., 2005). As the market is small and the policies are openly available, it is easy for the management of one company to differentiate it from another. Alternatively, the differences in the characterizations may be a result of designing the policy "to fit the circumstances pertaining to the specific company" as instructed by the stock exchange (Nasdaq Helsinki Ltd., 2016). In this case, these interpretations indicate what transparency does in the companies, in addition to describing what the company thinks transparency is (Christensen \& Cheney, 2015). Consequently, the disclosure policy gives an impression of a substantive rather than symbolic document (see Stevens et al., 2005).

Finally, it seems that Finnish companies strive to present themselves as intelligently transparent and different from others. Furthermore, they present themselves as being as transparent as required, although not necessarily as being as transparent as possible. However, judging by the characterizations of transparency, the idea of one-way communication is strongly represented in the data, even if the importance of interaction with the shareholders, investors, and other key stakeholders is recognized. In part, this comes from intertextual influence from authoritative sources, where communication is seen as a neutral transfer of information. Nevertheless, few of the companies investigated seem to emphasize dialogue or mutuality with their stakeholders (see Christensen \& Langer, 2009). 


\section{Conclusion}

There are some limitations to this study. In the autumn of 2015,13 of the 25 top companies on the OMXHelsinki25 list had a disclosure policy document publicly available on their IR websites. This indicates that there are different practices available for listed companies to construct an image of themselves as reliable business partners. Thus, a disclosure policy genre may not be the only way for Finnish companies to demonstrate their transparency. The alternative forms, the reasons for their use, and their efficiency in relation to an established genre would offer an interesting topic for further research, as would the international differences in the means of demonstrating transparency. The move analysis applied revealed disclosure policy to be a rather standardized genre, and therefore using the genre rhetorically in order to construct the intended image of the company, an image different from that of other companies, requires careful consideration and rhetorical awareness. Such internal company practices of transparency creation would be very interesting, albeit challenging, avenues for further research. What is more, research on the reception practices of disclosure policies and other forms of transparency creation would enable scholars to study the efficiency of the rhetorical choices made by the companies.

In discussions of transparency, a common concern is that descriptions of transparency and openness result in what could be called nominal transparency, thus making transparency a rhetorical construct with no counterpart in reality and company actions (Stevens et al., 2005). An illustration of nominal transparency could be a company publishing a standard version of disclosure policy on their IR website that might describe any company, and provide the reader no 
opportunity to determine what type of action the policy results in within the company. However, because disclosure policies are mostly read by an expert audience with the ability to see through empty rhetoric, companies need to consider carefully which expressions they select to describe their own principles.

It follows that the role of readers as judges of the rhetoric of the disclosure policy becomes crucial (see Christensen and Langer, 2009). Expert readers have the required interpretive capabilities to decide if the requirements of transparency are followed, and if not, to take action either by withdrawing their money from the company in question or by influencing the company's decision making to shift it in the required direction. As for shareholders and potential investors, this might also include actively working to reduce the degree of transparency according to their own interests. In any case, disclosure policy as a genre truly seems to serve the goals of transparency as it gathers statements of transparency to one document and is directed at expert readers able to see through the rhetoric. In order for there to be transparency, the readers must find the message and understand it. In essence, it is a question of two-way communication and not transfer of content controlled by the companies; only then can there be the openness that leads to transparency and ultimately to trust.

\section{References}

Albu, O. B., \& Wehmeier, S. (2014). Organizational Transparency and Sense-Making: The Case of Northern Rock. Journal of Public Relations Research, 26(2), 117-133, doi: 10.1080/1062726X.2013.795869

Askehave, I., \& Swales, J. M. (2001). Genre Identification and Communicative Purpose: A Problem and a Possible Solution. Applied Linguistics 22(2), 195-212. 
Bazerman, C., (2004). Intertextuality: How texts Rely on other Texts. In C. Bazerman \& P. Prior (Eds.), What Writing Does and How it Does it? An Introduction to Analyzing texts and textual Practices (pp. 83-96). Mahwah, New Jersey, London: Lawrence Erlbaum Associates.

Bhatia, V. K. (1993). Analysing Genre. Language Use in Professional Settings. London: Longman.

Bhatia, V. K. (2004). Worlds of written discourse. London: Continuum.

Bhatia, V. K. (2010) Interdiscursivity in professional communication. Discourse \& Communication, 21(1), 32-50.

Catenaccio, P. (2008). Press Releases as a Hybrid Genre: Addressing the Informative/Promotional Conundrum. Pragmatics 18(1), 9-31.

Chiu, Y-L. T. (2016). 'Singing your tune': Genre structure and writer identity in personal statements for doctoral applications. Journal of English for Academic Purposes, 21, 48-59. doi: 10.1016/j.jeap.2015.11.001.

Christensen, L. T., \& Cheney, G. (2015). Peering into Transparency: Challenging Ideals, Proxies, and Organizational Practices. Communication Theory, 25, 70-90.

Christensen, L. T., \& Langer, R. (2009). Public relations and the strategic use of transparency. Consistency, hypocrisy and corporate change. In R. L. Heath, E. Toth, \& D. Waymer (Eds.), Rhetorical and critical approaches to public relations II (pp. 129-153). Hillsdale, NY: Routledge.

Cornut, F., Giroux, H., \& Langley, A. (2012). The strategic plan as a genre. Discourse \& Communication $6(1), 21-54$.

Crawford Camiciottoli, B. (2014). Rhetoric in financial discourse. A linguistic analysis of ICT-mediated disclosure genres. Amsterdam/New York: Rodopi.

Ditlevsen, M. G. (2014). Building Up Trust in Good Times and in Bad Times: On Investor Relations from a communication perspective. In M. Stumpf, \& S. Wehmaier (Eds.), Kommunikation in Change und Risk: Wirtschaftskommunikation unter Bedingungen von Wandel und Unsicherheiten (Europäische Kulturen in der Wirtschaftskommunikation, Vol. 18) (pp. 291-305). Wiesbaden: Springer-VS.

Ditlevsen, M. G., \& Kastberg, P. (2007). When Corporate Communication Goes Public: Communication Policies in Public Communication. Hermes - Journal of Language and CommunicationStudies 38, $11-40$.

Dudley-Evans, A. (1986). Genre analysis: an investigation of the introduction and discussion sections of MSc dissertations. In M. Coulthard (Ed.), Talking about text, Discourse Analysis Monograph No. 13 (pp. 128-145). Birmingham: English Language Research, University of Birmingham.

Fairclough, N. (1992). Discourse and Social Change. Cambridge: Polity Press.

Fairclough, N. (2003). Analysing Discourse: Textual Analysis for Social Research. London and New York: Routledge. 
Financial Supervisory Authority (2008). Standard 5.2b. Disclosure obligation of the issuer and shareholder. Retrieved from

http://www.finanssivalvonta.fi/en/Regulation/Regulations/New/Obsolete/Documents/5.2b.std6.pdf

Financial Supervisory Authority (2013a). Disclosure policy. Retrieved from

http://www.finanssivalvonta.fi/en/Listed_companies/Listing/Disclosure_policy/Pages/Default.aspx. Cited 2.8.2016.

Financial Supervisory Authority (2013b). Market Newsletter 3/2013.Retrieved from http://www.finanssivalvonta.fi/en/Publications/Market/Documents/Market_newsletter_3_2013.pdf. Cited 20.11.2016.

Financial Supervisory Authority (2013c). Regulations and guidelines 7/2013. Disclosure obligation on issuers. Retrieved from

http://www.finanssivalvonta.fi/en/Regulation/Regulations/New/Obsolete/Documents/7_2013_EN.p df. Cited 18.11.2016.

Financial Supervisory Authority (2016). Regulations and guidelines 6/2016. Regulations and guidelines on disclosure obligation. Retrieved from http://www.finanssivalvonta.fi/en/Regulation/Regulations/New/Documents/2016_06.M1_en.pdf. Cited: 20.11.2016.

Garzone, G. (2012). Why Do Genres Change? In G. Garzone, P. Catenaccio, \& C. Degano (Eds.), Genre Change in the Contemporary World. Short-term Diachronic Perspectives (217-242). Bern etc.: Peter Lang.

Gilsdorf, J. W. (1987). Written Corporate Communication Policy: Extent, Coverage, Costs, Benefits. Journal of Business Communication 24(4), 35-52.

Gilsdorf, J. W. (1992). Written Corporate Policy on Communicating: A Delphi Survey. Management Communication Quarterly, 5(3), 316-347.

Guimard, Anne (2008). Investor Relations. Principles and International Best Practices of Financial Communications. London, New York: Palgrave Macmillan.

Hansen, H. K., Christensen, L. T., \& Flyverbom, M. (2015). Introduction: Logics of transparency in late modernity: Paradoxes, mediation and governance. European Journal of Social Theory, 18(2) 117 131.

Jarzabkowski, P., \& Whittington, R. (2008). A Strategy-as-Practice Approach to Strategy Research and Education, Journal of Management Inquiry, 17 (4), 282-286.

Koskela, M. (2013). Same, same, but different - intertextual and interdiscursive features of communication strategy texts. Discourse \& Communication, 7(4), 1-19.

Koskela, M., \& Kuronen, M-L. (2014). The essence of a hybrid genre: The causes of variation in corporate disclosure policies. In G. Budin \& V. Lušicky (eds.), Languages for Special Purposes in a Multilingual Transcultural World, Proceedings of the 19th European Symposium on Languages for Special Purposes, 8-10 July 2013, Vienna, Austria. http://sp2013.univie.ac.at/proceedings 
Market Abuse Regulation (EU) (MAR) (2014). Regulation (EU) No 596/2014 of the European Parliament and of the Council of 16 April 2014 on market abuse (market abuse regulation). Retrieved from http://eur-lex.europa.eu/legalcontent/EN/TXT/PDF/?uri=CELEX: 32014R0596\&from=fi. Cited 15.11.2016.

McCabe, D. (2010). Strategy-as-Power: Ambiguity, Contradiction and the Exercise of Power in a UK Building Society. Organization, 17(2): 151-175.

Nasdaq Helsinki Ltd (2016). Rules of the Exchange 1 March 2016 (Replaces Rules effective 1 December 2015) Unofficial translation. Retrieved from http://business.nasdaq.com/Docs/Nasdaq-HelsinkiRules-of-the-Exchange_EN_20160301.pdf.

Ohlsson, C. (2011). The roles of intertextual relations in corporate codes of conduct. Paper presented at 27th EGOS Colloquium. Göteborg 6-9 july, 2011.

O’Neill, O. (2006). Transparency and the ethics of communication. In C. Hood \& D. Heald (Eds.), Transparency: Key to a better governance (pp. 75-90). Oxford, UK: Oxford University Press.

Securities Markets Act (746/2012) (2012). Retrieved from http://www.finlex.fi/fi/laki/kaannokset/2012/en20120746.pdf. Cited 21.11.2016.

Stevens, J. M., Steensma, H. K, Harrison, D. A, \& Cochran P. L. (2005). Symbolic or substantive document? The influence of ethics codes on financial executive's decisions. Strategic Management Journal 26, 181-195.

Steyn, Benita (2000). Model for developing corporate communication strategy. Communicare, (19)2, 133.

Steyn, Benita (2003). From strategy to corporate communication strategy: A conceptualization. Journal of Communication Management, 8(2), 168-183.

Swales, J. M. (1981). Aspects of Article Introductions. Birmingham: University of Aston.

Swales J.M. (1990). Genre Analysis: English in Academic and Research Settings. Cambridge: Cambridge University Press.

Transparency Directive (2004/109/EC). Retrieved from http://eur-lex.europa.eu/legal-content/EN/TXT/ ?qid= 1433341141730\&uri=CELEX:02013L0050-20131126.

Upton T.A., \& Cohen M.A. (2009). An approach to corpus-based discourse analysis: The move analysis as example. Discourse Studies, 11(5), 585-605.

Vaara, E., Sorsa, V., \& Pälli, P. (2010). On the force potential of strategy texts: a critical discourse analysis of a strategic plan and its power effects in a city organization. Organization, 17(6): 685702.

Xerox (2001/2008). Xerox Corporation Disclosure Policy and Guidelines. Retrieved from: https://www.news.xerox.com/investors/disclosure. Cited 20.11.2016. 

APPENDIX 1. Characterizations of types of information and ways of delivering it.

Definitions of types of information and ways of delivering it as defined by the Securities Markets Act of Finland, Nasdaq OMX Helsinki and FSA (NB! not all recommendations are available in English).

\begin{tabular}{|l|l|}
\hline Type of information & $\begin{array}{l}\text { How information should be } \\
\text { given }\end{array}$ \\
\hline Accurate & Equally \\
\hline Clear & Impartially \\
\hline Comparable & In logical form \\
\hline Comprehensive & $\begin{array}{l}\text { Provided in accordance with the } \\
\text { rules of the Exchange }\end{array}$ \\
\hline Correct & Simultaneously to all parties \\
\hline Easily comprehensible & Without undue delay \\
\hline Essential & \\
\hline High-quality & \\
\hline Internal and external & \\
\hline $\begin{array}{l}\text { Likely to affect the value of } \\
\text { security }\end{array}$ & \\
\hline Non-misleading & \\
\hline Relevant & \\
\hline Reliable & \\
\hline Sufficient & \\
\hline Timely & \\
\hline Up-to-date & \\
\hline & \\
\hline
\end{tabular}

